\title{
Turkish adaptation of the undergraduate nursing clinical evaluation form: a validity and reliability study
}

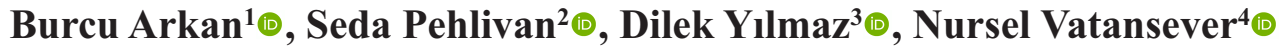 \\ ${ }^{I}$ Department of Psychiatric Nursing, Bursa Uludag University Faculty of Health Sciences, Bursa, Turkey \\ ${ }^{2}$ Department of Internal Medicine Nursing, Bursa Uludag University Faculty of Health Sciences, Bursa, Turkey \\ ${ }^{3}$ Department of Fundamentals of Nursing, Bursa Uludag University Faculty of Health Sciences, Bursa, Turkey \\ ${ }^{4}$ Department of Surgical Nursing, Bursa Uludag University Faculty of Health Sciences, Bursa, Turkey
}

\section{ABSTRACT}

Objectives: The study was conducted for the purpose of determining the validity and reliability of the "Undergraduate Nursing Clinical Evaluation Form (CEF)" in a Turkish sample.

Methods: One hundred sixty-seven students enrolled in Faculty of Health Sciences Department of Nursing participated in the study. Study data were collected via the Student Description Form and CEF. The Cronbach's $\alpha$ internal consistency coefficient was calculated for the reliability of the total scale. Pearson correlation analysis was used to determine the correlation between items and total scores.

Results: In the validity of the scale, CFA was used to investigate the consistency of the scale with the original scale. When the fit indices of the model tested using CFA were examined, it was seen that the chi-square value was significant. When the Cronbach's $\alpha$ reliability coefficients were examined, the reliability of the form was found to be quite good in terms of domains and total score. The correlations between the items and total scale score ranged between 0.42 and 0.77 . Cronbach's $\alpha$ coefficient was greater than 0.90 for each item.

Conclusions: Undergraduate Nursing Clinical Evaluation Form is a valid and reliable tool that can be used in the Turkish culture.

Keywords: Nursing, clinical evaluation, validity, reliability

T heoretical knowledge and clinical teaching are inseparable parts of nursing education as in the education programs of all practice-based disciplines [1, 2]. Students gain professional confidence in the fields where clinical teaching is applied. Clinical practice provides students the opportunity to integrate the theoretical knowledge and practice taught in the school by experiencing and practicing in a real environment. It also allows students to use their knowledge in a realworld environment, develop their psychomotor skills, and improve professional relationships [3, 4]. In clinical practice, students have the opportunity to practice what they learn and to see role models that prepare them for the future. At the same time, they develop critical thinking and problem-solving skills and receive the opportunity to see the relationships between health team members [4-7].

Factors such as the type of clinical setting, attitudes, and the experiences of the instructor are important in shaping the clinical experience of students [8]. Relevant studies have focused on identifying students' current and previous clinical practice experiences, and their perceptions of the clinical training process $[1,9$, 10-12]. In the study conducted by Chan [13], it was 
reported that clinical practice environments could not provide a positive learning environment for students. In the study conducted by Papathanasiou et al. [14] in order to evaluate nursing students' perceptions of clinical learning environments, it was determined that there was a significant gap between the students' expectations of the clinical learning environment and the reality. As a result of the study, it was recommended that the education framework be reorganized. In another study, it was stated that instructors and nurses in the clinic play a particularly important role in integrating nursing students into the clinical environment during clinical practice [15]. In a qualitative study conducted by Serçekuş and Başkale [16] in Turkey, it was determined that nursing students were negatively affected if feedback was given by instructors in front of patients. In the study conducted by Arkan et al. [17], it was emphasized that the most significant factor in students' clinical learning was the attitude of instructors.

During clinical practices, the psychomotor skills students have acquired previously are evaluated alongside their cognitive and affective capacities [18]. The evaluation of students during clinical practice is one of the main focuses of nursing education, in order to ascertain that clinical learning goals have been met. Evaluation is an inseparable part of education and is a dynamic process that aims to ensure students learn and develop $[19,20]$. On the other hand, students are also expected to give feedback about their experiences after the clinical practice. It is very important for the evaluation process that educators be provided with feedback that adequately represents the views of the students because health care organizations require student feedback to shape educational programs and activities for personal development [8].

There are limited evaluation tools that nursing students can use to provide feedback at the end of clinical practice. In addition, it has been reported that some tools available are problematic in terms of their ability to provide correct evaluation, since they are hard to understand and there are too many deficiencies in the open-ended question format $[21,22]$. Therefore, there is a need to develop a tool that can provide feedback which helps instructors to provide a successful clinical practice environment. It was determined in the literature review that there is no evaluation tool that nursing students in Turkey can use to give feedback about their clinical practice. It is thought that the use of a measurement tool in which nursing students evaluate the current state of clinical practice in all its aspects will contribute to identify and solve problems in clinical training.

This study was thus conducted to test the Turkish validity and reliability of the Undergraduate Nursing Clinical Evaluation Form (CEF) developed by Porter et al. [8].

\section{Research Questions}

Is the Undergraduate Nursing Clinical Evaluation Form (CEF) for nursing students valid and reliable?

\section{METHODS}

The study was conducted methodologically with nursing students between December 2018 and January 2019.

The sample of the research consisted of second, third and fourth-year students at the Nursing Department of the Faculty of Health Sciences at Bursa Uludag University at the end of the fall semester of the 2018-2019 academic year. Among the students included in the sample, second-year students had completed internal medicine nursing internship practices; third-year students had completed obstetrics and gynecology nursing internship practices; and fourth-year students had completed public health nursing, psychiatric nursing, and surgical diseases nursing internship practices. First-year nursing students were excluded from the research since they had not yet had clinical practice experience at the time of the study.

In the literature, three rules are mentioned for the determination of the sample size in validity and reliability studies. It is emphasized that at least five people should be included per item in order to perform factor analysis. Itis recommended that there be 10 people per item if there is no problem in reaching the sample [23]. If there is a serious limitation in sampling it is recommended that the size of the sample be at least 100 people. Ten students were included per item in order to perform the validity and reliability study of the 30item CEF, and the size of the sample was calculated as 210 students. Two hundred twenty students who met the research criteria were included in the sample. However, 53 students were excluded from the sample 
since they did not fully complete the form and analyses were performed on 167 students. The percentage of the sample reached was $75 \%$.

\section{Data Collection Tools}

The data of the research were collected using the Student Introduction Form and the CEF.

\section{Student Introduction Form}

This form includes questions about the age, gender, year-of-study, and clinical practice fields of the students.

\section{Undergraduate Nursing Clinical Evaluation Form (CEF)}

This was developed by Porter et al. [8] in 2011. It is an evaluation tool that can be used by nursing students to provide feedback at the end of the clinical practice process. The form consists of 21 items and five domains. The domains are "Orientation", "Clinical Educator/Teacher", "Ward Staff and Environment", "Clinical Hurdles" and "University". The form has a 5 -point Likert type ( $1=$ never, $2=$ rarely, $3=$ sometimes, $4=$ often, $5=$ always). The lowest score that can be obtained from the form is 21 and the highest score is 105 . The Cronbach's $\alpha$ value of the form is 0.90 [8].

\section{Data Collection}

\section{Language Validity}

For language validity, the form was translated from English to Turkish independently by three Turkish linguistic scientists. Afterward, the researchers evaluated the most appropriate translation for each item and prepared a common Turkish text. The scale, which was translated into Turkish, was retranslated to English by two linguistic scientists who were fluent in both Turkish and English and the translated form was compared with the original form. Inappropriate statements were revised to ensure language validity.

\section{Content Validity}

After language validity had been ascertained, the draft form was presented to 10 experts in psychiatry, internal medicine, surgery, nursing principles, pediatric nursing, and nursing management to obtain their opinions. The experts were asked to evaluate the draft form in terms of both language and content. The ex- perts scored each item as follows: " 4 " if an item did not need to be changed; " 3 " if a minor change was recommended; "2" if a major change was recommended; and " 1 " if it was recommended that an item be removed for being inappropriate.

\section{Application Process}

The draft scale developed was given nursing students who were not included in the sample for a pilot application and its intelligibility and the application process were evaluated.

\section{Construct Validity}

Confirmatory Factor Analysis (CFA) was used to validate the factors present in the original form of the scale for construct validity. Prior to the analysis, the data set was examined and missing data, extreme values, and normality were checked. The data were analyzed using the lavaan 0.6-3 package in the CFA RStudio Desktop 1.2.1335 for the construct validity of the scale.

\section{Determination of Reliability}

To determine the reliability of the CEF, which was developed by Porter et al. and consists of 21 items and 5 domains (orientation, clinical educator/teacher, ward staff and environment, clinical hurdles, and university), the Cronbach's $\alpha$ reliability coefficients were calculated from among the internal consistency methods and item-total score analyses were performed.

The students were asked to fill out the questionnaire given by the researchers. Care was taken that the time taken to complete questionnaires did not interfere with students' lecture hours. The maximum length of time it took for students to complete the form was calculated to be 15 minutes. The completed questionnaires were collected and evaluated.

\section{Ethical Consideration}

Written permission was obtained by email from the corresponding author Joanne Porter, who developed the form, in order to use the CEF in the research. Written permission was obtained from the Health Sciences Research and Publication Ethics Committee of Bursa Uludag University (Decision No: 2018-06). Students who agreed to participate in the research were informed that all of the data would be used for scientific purposes and that their answers would not affect 
their course marks in any way. Their informed consent was then obtained.

\section{Statistical Analysis}

Statistical analysis of the data was performed in the SPSS 23.0 (IBM Corp. Released 2015. IBM SPSS Statistics for Windows, Version 23.0. Armonk, NY: IBM Corp.) statistics package program. The demographic data of the students were presented as frequency and percentage for qualitative variables and mean and standard deviation for qualitative variables. The Cronbach's $\alpha$ internal consistency coefficient was calculated for the reliability of the total scale and five domains. Pearson correlation analysis was used to determine the correlation between items and total scores. In the validity of the scale, CFA was used to investigate the consistency of the scale with the original scale. Prior to the analysis, the data set was examined and missing data, extreme values, and normality were checked. The data were analyzed using the lavaan 0.63 package in the CFA RStudio Desktop 1.2.1335 for the construct validity of the scale. In the interpretation of the CFA result, the ratios of the chi-squared value to the degree of freedom, CFI, RMSEA, and SRMR fit indices were used. The significance level was accepted as $\alpha=0.05$.

\section{RESULTS}

The sociodemographic characteristics of the nursing students included in the study are given in Table 1. When the students evaluated their clinical practice with the CEF, it was determined that the highest score was in the "clinical educator/teacher" domain and the lowest score was in the "ward staff and environment" domain (Table 2).

Construct Validity of Undergraduate Nursing Clinical Evaluation Form (CEF)

When the fit indices of the model tested using CFA were examined, it was seen that the chi-square value was significant $(\chi 2=370.543 ; p<0.001)$. Fit indices and acceptable values obtained in the study are given in Table 3. According to these results, it was determined that the $\chi 2 / \mathrm{sd}, \mathrm{CFI}$, SRMR, and RMSEA values were within the acceptable limits and that the study provided construct validity.
Table 1. Sociodemographic characteristics of students

\begin{tabular}{lcc}
\hline Characteristics & n & \% \\
\hline Year & & \\
\hline \multicolumn{1}{l}{ Second } & 77 & 46.1 \\
\hline Third & 57 & 34.1 \\
\hline Fourth & 33 & 19.8 \\
\hline Age & & \\
\hline 18-23 & 160 & 95.8 \\
\hline $24-29$ & 6 & 3.6 \\
\hline 30-35 & 1 & 0.6 \\
\hline Gender & & \\
\hline Male & 31 & 18.6 \\
\hline Female & 136 & 81.4 \\
\hline Educational Status & & \\
\hline High School & 28 & 16.8 \\
\hline Vocational High School & 39 & 23.4 \\
\hline Anatolian-Science High School & 100 & 59.9 \\
\hline Income status & & \\
\hline Bad & 21 & 12.6 \\
\hline Medium & 130 & 77.8 \\
\hline Good & 16 & 9.6 \\
\hline Working status & & \\
\hline Working & 14 & 8.4 \\
\hline Not working & 153 & 91.6 \\
\hline Total & 167 & 100.0 \\
\hline
\end{tabular}

Reliability of Undergraduate Nursing Clinical Evaluation Form (CEF)

The reliability coefficient obtained in the study of Porter et al. [8] and reliability coefficients obtained in our study are given in Table 4. When the Cronbach's $\alpha$ reliability coefficients were examined, the reliability of the form was found to be quite good in terms of domains and total score. Pearson's Moment Correlation Coefficient was calculated for the CEF items used in the study and the internal consistency of each item with the scale as a whole was determined (Table 5). The correlations between the items and total scale score ranged between 0.42 and 0.77 , and the Cronbach's $\alpha$ coefficient was greater than 0.90 for each item. According to the results of the item analysis, it was found that the reliability of the form was good. 
Table 2. Frequency distribution of the clinical evaluation form scores

\begin{tabular}{|c|c|c|c|c|c|c|}
\hline Domains/Items & $\begin{array}{l}\text { Never } \\
\text { n (\%) }\end{array}$ & $\begin{array}{c}\text { Rarely } \\
\text { n (\%) }\end{array}$ & $\begin{array}{c}\text { Sometimes } \\
\text { n (\%) }\end{array}$ & $\begin{array}{l}\text { Often } \\
\text { n (\%) }\end{array}$ & $\begin{array}{c}\text { Always } \\
\text { n (\%) }\end{array}$ & Mean \pm SD \\
\hline \multicolumn{6}{|c|}{ Domain: Orientation } & $3.32 \pm 0.82$ \\
\hline $\begin{array}{l}\text { 1. Orientation was relevant and well } \\
\text { organized }\end{array}$ & $10(6)$ & $23(13.8)$ & $66(39.5)$ & $55(32.9)$ & $13(7.8)$ & $3.23 \pm 0.99$ \\
\hline $\begin{array}{l}\text { 2. I was made to feel welcome by the } \\
\text { educator }\end{array}$ & $5(3)$ & $15(9)$ & $55(32.9)$ & $69(41.3)$ & $23(13.8)$ & $3.54 \pm 0.94$ \\
\hline $\begin{array}{l}\text { 3. Clinical expectations were defined and } \\
\text { discussed during orientation }\end{array}$ & $13(7.8)$ & $24(14.4)$ & $63(37.7)$ & $50(29.9)$ & $17(10.2)$ & $3.2 \pm 1.06$ \\
\hline Domain: Clinical educator/Clinical teacher & & & & & & $3.59 \pm 0.76$ \\
\hline $\begin{array}{l}\text { 4. The educator was available and easily } \\
\text { contactable during placement }\end{array}$ & $2(1.2)$ & $19(11.4)$ & $58(34.7)$ & $53(31.7)$ & $35(21)$ & $3.6 \pm 0.98$ \\
\hline $\begin{array}{l}\text { 5.The educator was approachable and } \\
\text { friendly }\end{array}$ & $3(1.8)$ & $16(9.6)$ & $46(27.5)$ & $69(41.3)$ & $33(19.8)$ & $3.68 \pm 0.96$ \\
\hline $\begin{array}{l}\text { 6.Debriefing sessions were relevant and } \\
\text { educational. }\end{array}$ & $4(2.4)$ & $17(10.2)$ & $65(38.9)$ & $51(30.5)$ & $30(18)$ & $3.51 \pm 0.98$ \\
\hline $\begin{array}{l}\text { 7.The in-service and educational sessions } \\
\text { were relevant }\end{array}$ & $5(3)$ & $14(8.4)$ & $63(37.7)$ & $54(32.3)$ & $31(18.6)$ & $3.55 \pm 0.99$ \\
\hline $\begin{array}{l}\text { 8. Rosters were available to me in a } \\
\text { reasonable timeframe }\end{array}$ & $8(4.8)$ & $17(10.2)$ & $47(28.1)$ & $57(34.1)$ & $38(22.8)$ & $3.6 \pm 1.09$ \\
\hline \multicolumn{6}{|c|}{ Domain: Ward staff/preceptors and ward environment } & $3.1 \pm 0.95$ \\
\hline 9.The staff were friendly and approachable & $8(4.8)$ & $33(19.8)$ & $59(35.3)$ & $49(29.3)$ & $18(10.8)$ & $3.22 \pm 1.04$ \\
\hline 10.I was made to feel welcome on the ward & $11(6.6)$ & $32(19.2)$ & $49(29.3)$ & $56(33.5)$ & $19(11.4)$ & $3.24 \pm 1.09$ \\
\hline $\begin{array}{l}\text { 11.The staff facilitated learning } \\
\text { opportunities for me }\end{array}$ & $8(4.8)$ & $27(16.2)$ & $60(35.9)$ & $46(27.5)$ & $26(15.6)$ & $3.33 \pm 1.07$ \\
\hline $\begin{array}{l}\text { 12.The staff involved me in clinical decision } \\
\text { making }\end{array}$ & $37(22.2)$ & $48(28.7)$ & $36(21.6)$ & $34(20.4)$ & $12(7.2)$ & $2.62 \pm 1.24$ \\
\hline \multicolumn{6}{|l|}{ Domain: Final assessment/clinical hurdles } & $3.26 \pm 0.93$ \\
\hline $\begin{array}{l}\text { 13. Clinical hurdles were achieved in } \\
\text { corporation with the clinical educator }\end{array}$ & $7(4.2)$ & $26(15.6)$ & $54(32.3)$ & $56(33.5)$ & $24(14.4)$ & $3.38 \pm 1.05$ \\
\hline $\begin{array}{l}\text { 14.Clinical hurdles were achievable within } \\
\text { the time frame of the clinical placement }\end{array}$ & $10(6)$ & $26(15.6)$ & $58(34.7)$ & $55(32.9)$ & $18(10.8)$ & $3.27 \pm 1.04$ \\
\hline $\begin{array}{l}\text { 15.An interim evaluation of clinical } \\
\text { competencies was conducted and goals set } \\
\text { for the remainder of placement }\end{array}$ & $15(9)$ & $29(17.4)$ & $55(32.9)$ & $53(31.7)$ & $15(9)$ & $3.14 \pm 1.09$ \\
\hline $\begin{array}{l}\text { 16. During the final evaluation I received } \\
\text { constructive feedback }\end{array}$ & $17(10.2)$ & $18(10.8)$ & $58(34.7)$ & $57(34.1)$ & $17(10.2)$ & $3.23 \pm 1.1$ \\
\hline \multicolumn{6}{|l|}{ Domain: University } & $3.4 \pm 0.82$ \\
\hline $\begin{array}{l}\text { 17. The clinical placement details were } \\
\text { made available prior to commencement of } \\
\text { the placement }\end{array}$ & $9(5.4)$ & $19(11.4)$ & $68(40.7)$ & $52(31.1)$ & $19(11.4)$ & $3.32 \pm 1$ \\
\hline $\begin{array}{l}\text { 18. Clinical hurdles. assessment tasks and } \\
\text { University expectations were outlined by } \\
\text { unit coordinator }\end{array}$ & $5 \% 3)$ & $17(10.2)$ & $68(40.7)$ & $53(31.7)$ & $24(14.4)$ & $3.44 \pm 0.96$ \\
\hline $\begin{array}{l}\text { 19. A contact person was available to } \\
\text { answer clinical questions }\end{array}$ & $8(4.8)$ & $17(10.2)$ & $46(27.5)$ & $67(40.1)$ & $29(17.4)$ & $3.55 \pm 1.05$ \\
\hline $\begin{array}{l}\text { 20. The clinical office was approachable and } \\
\text { friendly }\end{array}$ & $15(9)$ & 19 (11.4) & $53(31.7)$ & $59(35.3)$ & $21(12.6)$ & $3.31 \pm 1.11$ \\
\hline $\begin{array}{l}\text { 21. The placement was relevant to the unit } \\
\text { content }\end{array}$ & $7(4.2)$ & $21(12.6)$ & $59(35.3)$ & $58(34.7)$ & $22(13.2)$ & $3.4 \pm 1.01$ \\
\hline
\end{tabular}

Table 3. Confirmatory factor analysis fit indices

\begin{tabular}{lcc}
\hline Fit Indices & Turkish Form & Acceptable Values \\
\hline$\chi^{2} / \mathrm{SD}$ & 2.07 & $\leq 5$ \\
Comparative Fit Index (CFI) & 0.911 & $\geq 0.90$ \\
Standardized Root Mean Square Residuals (SRMR) & 0.059 & $\leq 0.080$ \\
Root Mean Square Error of Approximation (RMSEA) & 0.080 & $\leq 0.080$ \\
\hline
\end{tabular}


Table 4. Domains of CEF and Cronbach's $\alpha$ Reliability Coefficients

\begin{tabular}{lccc}
\hline Factors & Item number & Original Form & Cronbach $\boldsymbol{\alpha}$ coefficient \\
\hline Orientation & 3 & 0.77 & 0.77 \\
Clinical educator/clinical teacher & 5 & 0.76 & 0.82 \\
$\begin{array}{l}\text { Ward staff/preceptors and ward } \\
\text { environment }\end{array}$ & 4 & 0.91 & 0.88 \\
Final assessment/clinical hurdles & 4 & 0.73 & 0.89 \\
University & 5 & 0.79 & 0.86 \\
Total & 21 & 0.90 & 0.94 \\
\hline
\end{tabular}

Table 5. Results of Individual Item Analysis for CEF

\begin{tabular}{lcccc}
\hline & $\begin{array}{c}\text { Scale Mean } \\
\text { if Item is Deleted }\end{array}$ & $\begin{array}{c}\text { Scale Variance } \\
\text { if Item is Deleted }\end{array}$ & $\begin{array}{c}\text { Corrected Item-Total } \\
\text { Correlation }\end{array}$ & $\begin{array}{c}\text { Cronbach's Alpha } \\
\text { if Item Deleted }\end{array}$ \\
\hline Item 1 & 67.1377 & 197.372 & 0.525 & 0.936 \\
\hline Item 2 & 66.8263 & 196.482 & 0.587 & 0.935 \\
\hline Item 3 & 67.1617 & 193.389 & 0.622 & 0.935 \\
\hline Item 4 & 66.7665 & 194.144 & 0.649 & 0.934 \\
\hline Item 5 & 66.6886 & 194.517 & 0.653 & 0.934 \\
\hline Item 6 & 66.8503 & 194.646 & 0.631 & 0.934 \\
\hline Item 7 & 66.8144 & 194.453 & 0.635 & 0.934 \\
\hline Item 8 & 66.7665 & 198.614 & 0.425 & 0.938 \\
\hline Item 9 & 67.1497 & 194.297 & 0.606 & 0.935 \\
\hline Item 10 & 67.1257 & 192.653 & 0.627 & 0.935 \\
\hline Item 11 & 67.0359 & 194.444 & 0.578 & 0.935 \\
\hline Item 12 & 67.7485 & 194.876 & 0.478 & 0.938 \\
\hline Item 13 & 66.9820 & 190.259 & 0.746 & 0.932 \\
\hline Item 14 & 67.0958 & 189.425 & 0.779 & 0.932 \\
\hline Item 15 & 67.2216 & 188.957 & 0.756 & 0.932 \\
\hline Item 16 & 67.1317 & 190.766 & 0.686 & 0.933 \\
\hline Item 17 & 67.0479 & 196.564 & 0.546 & 0.936 \\
\hline Item 18 & 66.9222 & 194.000 & 0.671 & 0.934 \\
\hline Item 19 & 66.8144 & 192.297 & 0.673 & 0.934 \\
\hline Item 20 & 67.0539 & 191.244 & 0.662 & 0.934 \\
\hline Item 21 & 66.9641 & 194.204 & 0.630 & 0.934 \\
\hline I6 167, N0. & 6216 & &
\end{tabular}

$\mathrm{n}=167$, No. of Items $=21$, Cronbach's Alpha $=0.940$

\section{DISCUSSION}

In this study, conducted to determine the validity and reliability of the Turkish version of the CEF developed by Porter et al. [8], the opinions of ten experts about language and content validity were obtained The fit index of the form in terms of items and scale was found to be greater than 0.90 . The data obtained from the study shows that the language and content validity of the form was ensured and that the form measures 
the subject sufficiently.

Construct Validity of Undergraduate Nursing Clinical Evaluation Form (CEF)

The construct validity of the 21-item CEF and its five domains, (orientation, clinical educator/teacher, ward staff and environment, clinical hurdles, and university) was investigated through CFA. In the CFA, a number of fit indices are used to determine the construct validity of the scale. Fit indices are used in order to evaluate the fitness between the theoretical model and the actual data. Since the fit indices have different advantages compared to each other, it is recommended that more than one fit index be used in the CFA [24]. Accordingly, it was determined that the chi-square value of the model tested with the CFA was significant $(\chi 2=370.543 ; p<0.001)$. Moreover, it is stated that the possibility that the chi-square test will be significant may increase significantly with an increase in the sample size and it is recommended that the $\chi 2 / \mathrm{SD}$ ratio be considered [25]. In order to test which CFA model best represented the present dataset several fit indices were selected: root-mean-squared error of approximation (RMSEA) [26], comparative fit index (CFI) [27], chisquare, and change in chi-square/degrees of freedom between models [25]. RMSEA is a measure of the average of the residual variance and covariance; good models have RMSEA values that are at or less than 0.08 [8]. CFI is an index that falls between 0 and 1 , with values greater than 0.90 considered to be indicators of good fitting models [28]. In the current study, the $\chi 2 / \mathrm{SD}, \mathrm{CFI}, \mathrm{SRMR}$, and RMSEA values were found to be within acceptable limits. It can therefore be stated that the study provides construct validity.

\section{Reliability of Undergraduate Nursing Clinical Evaluation Form (CEF)}

The Cronbach's $\alpha$ coefficient indicates whether the items measure the same characteristic and whether the items are associated with the measured subject. This value should be as close to 1 as possible in scales. A value between 0.60 and 0.80 indicates that the scale is very reliable; a value between 0.80 and 1.00 indicates that the scale is highly reliable $[29,30,31,32$, $33,34]$. When the Cronbach's $\alpha$ reliability coefficients obtained in our study were examined, the reliability of the Turkish version of the Clinical Evaluation Form
(CEF) was found to be good in terms of the domains and the total score. In the original study, the Cronbach's $\alpha$ values of the form in terms of domains and total score were also found to be greater than 0.70 [8]. This result shows that the Turkish version of the form is similar to the original version and has a strong internal consistency.

The correlation coefficient is an indicator of whether the items in the scale measure the desired quality in item analysis [29-32, 34, 35]. This value should be greater than 0.20 in a positive direction [30]. In our study, the correlation of items with the total scale score ranged between 0.42 and 0.77 . Item-total score correlation coefficients were found to be in a positive direction and greater than 0.20 . According to these results, it can be stated that all items of the scale had a high correlation with total score, that the desired quality of the scale was measured sufficiently, and that the item reliability of the scale was high. Since itemtotal score correlations were not given in the original study, our results could not be compared with the original form [8].

\section{CONCLUSION}

In conclusion, clinical practice can only be successful if the instructor is able to comprehensively evaluate the process and eliminate any deficiencies. In this process, obtaining feedback from students about their clinical practice is very important. Thanks to this feedback, problems can be detected and the necessary precautions taken; thus, a more effective learning environment can be achieved. There is thus a need for a valid and reliable evaluation tool that students can use to correctly evaluate their experience of the process. This study has demonstrated that the Turkish version of the CEF is a valid and reliable measurement tool. It is suggested that nursing students use this form to evaluate clinical practice and thus eliminate a significant gap in this field.

\section{Authors' Contribution}

Study Conception: BA, SP, DY, NV; Study Design: BA, SP, DY, NV; Supervision: BA; Funding: BA, SP, DY, NV; Materials: BA, SP, DY, NV; Data Collection and/or Processing: BA, SP, DY, NV; Sta- 
tistical Analysis and/or Data Interpretation: BA, SP, DY, NV; Literature Review: BA, SP, DY, NV; BA, SP, DY, NV: BY, MOK, EP and Critical Review: BA, SP, DY, NV.

\section{Conflict of interest}

The authors disclosed no conflict of interest during the preparation or publication of this manuscript.

\section{Financing}

The authors disclosed that they did not receive any grant during the conduction or writing of this study.

\section{REFERENCES}

1. Karadağ G, Kılıç SP, Ovayolu N, Ovayolu Ö, Kayaaslan H. [Difficulties encountered by nursing students in practices and their views about nurses]. TAF Prev Med Bull 2013;12:665-72. [Article in Turkish]

2. Sharif F, Masoumi S. A qualitative study of nursing student experiences of clinical practice. BMC Nurs 2005;4:1-7.

3. Bisholt B, Ohlsson U, Engtrom AK, Johansson AS, Gustafsson M. Nursing students' assessment of the learning environment in different clinical settings. Nurse Educ Pract 2014;14:304-10.

4. Moonaghi HK, Mirhaghi A, Oladi S, Zeydi AE. A journey across an unwelcoming field: a qualitative study exploring the factors influencing nursing student's clinical education. Health Sci J 2015;9:1-7.

5. Ha EH. Attitudes toward clinical practice in undergraduate nursing students: a Q methodology study. Nurse Educ Today 2015;35:733-9.

6. Hassan S. Challenges in clinical learning: experiences of Maldivian nursing students. Maldives National J Res 2017;5:79-94. 7. O’Mara L, McDonald J, Gillespie M, Brown H, Miles L. Challenging clinical learning environments: experiences of undergraduate nursing students. Nurse Educ Pract 2014;14:208-13.

8. Porter J, Al-Motlaq M, Hutchinson C, Sellick K, Burns V, James A. Development of an undergraduate nursing clinical evaluation form (CEF). Nurse Educ Today 2011;31:58-62.

9. D'Souza MS, Karkada SN, Parahoo K, Venkatesaperumal R. Perception of and satisfaction with the clinical learning environment among nursing students. Nurse Educ Today 2015;35:83340 .

10. Midgley K. Pre-registration student nurses perception of the hospital-learning environment during clinical placements. Nurse Educ Today 2006;26:338-45.

11. Mthimunye KDT, Daniels FM. Student nurses' perceptions of their educational environment at a school of nursing in Western Cape province, South Africa: a cross-sectional study. Curationis 2019;42:e1-e11.

12. Taştekin A, Türkdönmez B, Güler M, Yılmaz A, Erşahan T. [Related factors and satisfaction levels of nursing students in clinical setting]. FN Hem Derg 2016;24:24-9. [Article in Turkish]
13. Chan D. Development of the clinical learning environment inventory: using the theoretical framework of learning environment studies to assess nursing students' perceptions of the hospital as a learning environment. J Nurs Educ 2002;41:69-75.

14. Papathanasiou IV, Tsaras K, Sarafis P. Views and perceptions of nursing students on their clinical learning environment: teaching and learning. Nurse Educ Today 2014;34:57-60.

15. Yonge O, Myrick F, Haase M. Student nurse stress in the preceptorship experience. Nurse Educ 2002;27:84-8.

16. Serçekuş P, Başkale H. Nursing students' perceptions about clinical learning environment in Turkey. Nurse Educ Pract 2016;17:134-8.

17. Arkan B, Ordin, Y, Y1lmaz D. Undergraduate nursing students' experience related to their clinical learning environment and factors affecting to their clinical learning process. Nurse Educ Pract 2018;29:127-32.

18. Arrigoni C, Grugnetti AM, Caruso R, Gallotti ML, Borrelli P, Puci M. Nursing students' clinical competencies: a survey on clinical education objectives. Ann Ig 2017;29:179-88.

19. Glick S, Fernandez L, Irby DM, Harleman E, Fernandez A. Teaching about health care disparities in the clinical setting. $\mathrm{J}$ Gen Int Med 2010;25(Suppl 2):95-101.

20. Nikbakht-Nasrabadi A, Mohammadpour A, Abbasi M, Javadi M. Iranian nursing students perspective of their rights in clinical evaluation: a thematic analysis study. Life Sci J 2012;9:5568-74. 21. Booth J, Collins S, Hammond A. Considered evaluation of clinical placements in a new medical school. Asses Eval High Educ 2008;34:7-29.

22. Penman J, Oliver M. Meeting the challenges of assessing clinical placement venues in a bachelor of nursing program. J Uni Teach Learn Pract 2004;1:59-73.

23. Tavşancıl E. Tutumların ölçülmesi ve SPSS ile veri analizi. Ankara: Nobel Yayın Dağıtım; 2010.

24. Kline RB. Principles and Practice of Structural Equation Modeling. 3rd ed. New York: The Guilford Press; 2011.

25. Büyüköztürk Ş, Akgün ÖE, Özkahveci Ö, Demirel F. The validity and reliability study of the Turkish version of the motivated strategies for learning questionnaire. Educational Scienses: Theory\&Practice 2004;4:231-9.

26. Browne MW, Cudeck R. Alternative ways of assessing model fit. Newbury Park, CA: Sage. 1993.

27. Bentler PM. Comparative fit indixes in structural models. Psychol Bull 1990;107:238-46.

28. Hu L, Bentler PM. Cutoff criteria for fit indices in covariance structure analysis: conventional criteria versus new alternatives. Struct Equ Modeling 1999;6:1-55.

29. Aksayan S, Gözüm S. [A guide for transcultural adaptation of the scale]. Hemşirelik Araştırma Dergisi 2002;4:9-14. [Article in Turkish]

30. Şencan H. Reliability and validity in social and behavioral measurement. 1. ed., Ankara: Seçkin Publishing, 2005.

31. Rattray J, Jones MC. Essential elements of questionnaire design and development. J Clin Nurs 2007;16:234-43.

32. Şimşek ÖF. Introduction to Structural Equation Modeling, LISREL Fundamental Principles and Practices. İstanbul: Ekinoks, 2010.

33. Hayran M. Basic statistic for health research. Art Ofset Mat- 
bacılık Yayıncilık Org. Ltd Şti, Ankara: 2011.

34. DeVellis RF. Scale development, theory and applications. 3rd ed. India: SAGE Publication Inc; 2012.

35. Terwee CB, Bot SD, de Boer MR, van der Windt DA, Knol
DL, Dekker J, et al. Quality criteria were proposed for measurement properties of health status questionnaires. J Clin Epidemiol 2007;60:34-42. 